\title{
Human Resource Outsourcing and Risk Management for SMEs
}

\author{
Shunhong Ji \\ Nanjing University of Science and Technology, Nanjing, China \\ m15651800599@163.com
}

Keywords: Human resource outsourcing; Risk management; Competitive advantage; SMEs

\begin{abstract}
Human resources outsourcing has become a major trend in HR management in small sized enterprises. It is becoming more important for business management. As an advanced management method, there must be high risk in this process. Thus, appropriate risk management is extremely necessary. In the study, we analyzed the status of human resources outsourcing in SMEs. Then, we took training outsourcing management and compensation outsourcing management as research subjects in order to discuss human resource outsourcing risk and procedures to control and avoid it. Ultimately, it will promote the development of enterprises by gaining advantages in the competition.
\end{abstract}

\section{Introduction}

In information age, the competition among enterprises turns into speed and time for technology and knowledge updating rapidly. However, due to constraints in size and funds, many SMEs do not set up human resources department and establish systematic personnel system. Under the circumstance, it is difficult to recruit high-quality employees for not providing employees with comprehensive benefits and training opportunities [1]. No strategic human resource planning will result in high turnover of key personnel and poor employees' satisfaction. Therefore, in the current domestic market, human resources outsourcing is still a challenge for SMEs. If managers take the first step to carry out human resource outsourcing to make up for their own deficiencies, it will substantially improve the human resource management level of enterprises and compete with others.

\section{Training Outsourcing Management}

Training plays an important role in the success of many companies, such as Edward Jones and Southwest Airlines, which is a model for successful global enterprise management. One of the key reasons for their success is focusing on staff training. With the increasing emphasis on employees' training and the development of outsourcing industry, many SMEs find that it is more practical to draw support from external professional companies in training employees than supporting a large number of training specialists within the enterprise [2]. At present, many companies are increasing outsourcing in training and development activities every year, hoping to control the training expenditure as much as possible while implementing larger-scale and higher-quality staff training.

Outsourcing can introduce some specialists into the organization and receive expertise. Due to rapid changes in technology and law, many human resource departments lacked internal resources and expertise to adapt to the changing external environment. The assistance from external training providers ensures that practices of staff are consistent with the needs of development. In addition, outsourcing can often improve the effectiveness and service level of the task. The contractor has offered both standard operating procedures and personnel with specialized KSAs. Moreover, the contractor is familiar with the selection and training program. Thus, when similar training programs are provided to different customers, it will bring about economies of scale and reduce the cost. Eventually, part of the cost saved will render to consultants and make the price decrease.

The following factors can be considered when concerning the effectiveness of the results related to training outsourcing: (i) establish a relationship of mutual trust with the contractor; (ii) take correct motivation for outsourcing; (iii) make a clear and comprehensive contract; (iv) collaborate closely with the training party in the implementation. 


\section{Compensation Outsourcing Management}

There may be many reasons for SMEs carrying out compensation outsourcing management. The most common reason is to ensure that the internal staff focused on activities related to the strategy. Secondly, managers choose to transfer technology investment to external service agencies. What's more, it is beneficial to enhance the ability to carry out the compensation management for SMEs. However, when considering and implementing compensation outsourcing, we must be clear about the objective and make careful assessment [3].

First, it is the determination of the goal of compensation outsourcing. Before deciding on outsourcing, it is essential to assess the current situation of compensation and mechanism of outsourcing. Beside advantages in cost control and core competence, organization has its own specific objectives, which should be considered for outsourcing.

Secondly, estimate on the cost of outsourcing. Compensation outsourcing often help large employers improve operational capacity and optimize cost. Therefore, it is necessary to ask the structure of contractor's price and add the estimated cost to the total cost, which facilitating price comparison. In addition, there is a need to identify penalties associated with the termination of services.

Finally, assess the contractor. As compensation in the human resources will involve some sensitive issues, therefore, it is critical to ensure the security reliability of outsourcing. It is important to understand the situation of the outsourcer before establishing contact with them, including the history of outsourcing, the ownership status and the experience in the outsourcing business and the proportion of business in its contracted income. All of this are reliable evidence that reflecting its strength and reliability. In addition, its recent financial situation and profitability is also a matter of concern [4].

\section{Risk Management of Human Resource Outsourcing for SMEs}

Organizational Factors. There are seven types of factors in organizational level. The relationship between organizational factors and different outsourcing activities is shown in table 1.

Table 1 Relationship between organizational characteristics and different outsourcing activities

\begin{tabular}{|l|c|c|c|c|}
\hline & $\begin{array}{c}\text { Comprehensive } \\
\text { Activities }\end{array}$ & $\begin{array}{c}\text { Human Capital } \\
\text { Activities }\end{array}$ & $\begin{array}{c}\text { Recruiting } \\
\text { Activities }\end{array}$ & $\begin{array}{c}\text { Trading } \\
\text { Activities }\end{array}$ \\
\hline Unique HR Practices & - & - & - & + \\
\hline Strategic HR Management & - & + & + & + \\
\hline Good HR effect & - & - & - & + \\
\hline Promotion Opportunity & - & - & - & - \\
\hline Uncertain Demand & + & + & + & + \\
\hline High-pay Policy & - & + & + & + \\
\hline Large sized companies & - & - & - & - \\
\hline
\end{tabular}

First of all, uniqueness of HR practices. According to the transaction cost economics, human resources outsourcing can be regarded as a kind of organizational structure in the form of market contract, which is opposite to the organizational hierarchy. Moreover, the implementation of unique HR practices may restrict the capability of contractors to provide satisfactory service [5]. As we know, economies of scale results from similar needs of multiple entrusting parties. While unique practices necessarily entail special investments, declining the economies of scale and affecting the cost advantage of outsourcing. Therefore, if the human resources practices are unique in the organization, it is less likely to outsource comprehensive, human capital, and recruiting activities, except for transactional activities.

Next, it is the strategic participation of HR. In recent years, there are more appeals for HR department to become business partners or play an important role in organizational performance strategy. Therefore, for strategic human resource managers, they will pay more attention on 
activities that are relevant to corporation strategy and require a better understanding of corporate practices and culture. Some routine activities, such as compensation and training, are less concerned. Thus, if the HR department plays a strategic role in the company, there will be greater outsourcing trend [6].

Thirdly, it's status of HR effectiveness. According to the resource theory, the availability of good human resources depends on tacit knowledge. In human resources management, tacit knowledge will spread within internal staff in leadership and guidance. Companies that have achieved good human resource outcomes will take less outsourcing in comprehensive, human capital, and recruiting activities and their trading activities will not be affected.

In addition, we will discuss about internal promotion opportunities for HR personnel. When carrying out HR activities, employees' pursuit of own goals at the expense of overall interests of the organization often occur, resulting in organizational costs. The solution to this problem depends on the existence of control mechanism and its function. Emphasizing internal promotion, namely providing career development channels, is an effective mechanism to control reduce the cost. When propagandizing opportunities for promotion, employees will make continued contribution to the organization. Accordingly, the organization can bear a lower internal HR cost, so the motivation for HR outsourcing is declined.

What's more, we should pay attention to uncertainty in HR requirements. The demand for labor has a potential impact on the cost of HR outsourcing. When demand changes, adjustments in cost are often required to redistribute these activities among employees. Therefore, companies faced with high HR demand uncertainty will take human resources outsourcing activities.

Payroll policy is also needed to be taken important consideration into our study. Because of differences in pay policies, the cost of human resource activities varies from one organization to another and may influence the benefit of internal management. In general, the cost of companies that implementing high-wage policy is usually higher [7]. It is more active in taking outsourcing activities, except for comprehensive activities.

In the final, it is the size of company. The size of enterprises has a negative impact on human resources outsourcing activities. The size of enterprises can influence the cost of outsourcing due to economies of scale. Many human resource services require specialized knowledge and skills, which require extensive training. Under normal circumstances, some companies occasionally need such services, particularly in small companies. SMEs may be more inclined to take human resource outsourcing for the unit cost of providing these services internally and infrequently use.

The Impact of Outsourcing Motivation. From the analysis above we know that even the same organizational factor will have different effect on different types of human resources activities outsourcing in the organization, which can be integrated into the following three main motivations: (i) establish and enhance the core competitiveness; (ii) reduce cost; (iii) handle risk; Some human resources activities closely related to core competitiveness and business performance, such as recruitment and training of core staff, are of great significance [8]. Enterprises tend to be cautious to these organizational activities and worry about lack of professional companies in related areas, so they often choose outsourcing to reduce the risk associated with this and access to quality service.

\section{Risk Analysis on Human Resources Outsourcing}

The first is risk in the enterprise's own ability. The ability of enterprises including outsourcing decision-making ability, ability to adapt to the changes brought by outsourcing and negotiation ability of contract negotiation team and management ability of contract relationship management team as well as the ability of monitoring HRM outsourcing effectively. SMEs are often in a passive position in the outsourcing activities due to the lack of capacity above and inadequate preparation. As a result, these SMEs can not monitor and control effectively, leading to the failure of outsourcing.

Secondly, risk in the response from the public and employees. When taking HRM outsourcing, it will inevitably raise staff's attention. On the one hand, they worry about losing jobs. The 'big 
family' feeling will gradually disappear and work enthusiasm will decrease as well. On the other hand, after outsourcing, employees will feel controlled by outside contractor and result in resistance, which is adverse to the development of enterprises. SMEs should enlighten the thought of staff in the department outsourced and take appropriate ways to improve their enthusiasm in order to make them play a key role in the outsourcing process.

The third is risk in the supplier selection. Owing to information asymmetry, there is high risk in the selection of HRM outsourcing supp liers. In accordance with the point of game, the service partner corporatizing with is not often what they want [9]. The key to the success of HRM outsourcing lies in the choice of contractors who have management expertise and rich contracting experience. They are able to manage these activities efficiently and effectively by faster and better procedures. Compared with large enterprises, SMEs has disadvantages in choosing contracting partners for its funds and social concern. In this way, managers in SMEs understand the situation of outsourcing companies only by themselves. This often leads to information inaccuracy and wrong decision made by enterprises, affecting the progress of outsourcing activities and even leading to the failure of outsourcing.

The last is risk in the culture communication. The risk of cultural communication is a major obstacle in the outsourcing of HRM. An enterprise has its own unique culture and values, which determined by the history of organization and the style of entrepreneurial. Even if there is no significant business culture in SMEs, managers must continue to build and strengthen it for further development. At this point, due to outsourcer's lack of understanding of corporate culture, it will inevitably lead to communication barriers and even the failure of outsourcing, that is, back-sourcing. What's more, to ensure the normal operation of enterprises, SMEs must continue to monitor the behavior of contracting enterprises and establish long-term, stable and mutual cooperative relationship.

\section{Procedures for Risk Management}

To carry out the risk management of human resources outsourcing, we must follow certain procedures, specific steps are shown in Fig. 1:

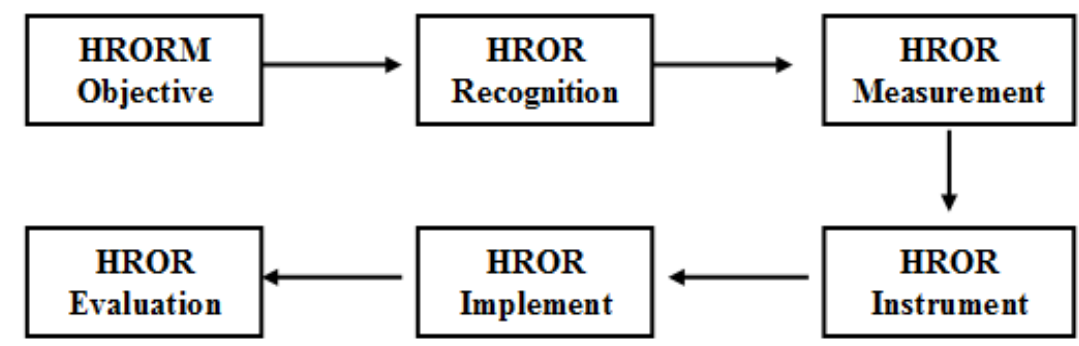

Figure 1. Procedures for risk management in HRM outsourcing

The main goal of human resource outsourcing risk management is to handle and control risk and reduce and avoid losses, in order to maintain the smooth progress of human resource management outsourcing activities and promote the core competitiveness of enterprises.

\section{Approaches for Risk Management}

Firstly, Outsourcing decisions. Determining the HRM content which is suitable for outsourcing is the basis for judging success or failure of outsourcing. It is generally accepted that outsourcing is not suitable for businesses that have the following characteristics: (i) human resource management is seen as a core competence in the enterprise; (ii) it is difficult for external suppliers to provide effective support in that some of the HRM functions are too confidential or unique; (iii) the human resources have not experienced outsourcing services, so it can not manage external contractors effectively; There will be only one or two business outsourcing in SMEs, such as training and 
compensation,in some specific cases, some projects will be outsourced to reduce the risk.

Secondly, selection of HRM outsourcing suppliers. How to choose suppliers is the most critical problem in human resource management outsourcing. When selecting a contractor, we should consider its strength and credit record firstly, Even if SMEs do not have the financial resources to find such a company, but also to be able to find a supplier with a detailed goal, plan and run. In addition, the HR manager should take initiative to participate in the outsourcing, because the new system will be operated by the human resources department and suppliers jointly. If the two sides suspend the relationship in the middle of the process, it will lead to a paralysis to the entire system. Therefore, in the choice of suppliers, the most important thing is to analyze its credit, services and whether meet the needs of the company [10]. Moreover, they can consult with customers who have recently (nearly 6 months) corporate with outsourcers or for a certain length of time to gain more comprehensive information and evaluate suppliers fully.

Uitimately, establish risk warning management system. In the HRM outsourcing risk management, the establishment of risk-taking warning management system enables enterprises to focus on changes in the outsourcing process and take preventive measures to reduce business losses. It provides a reasonable basis for business operators' decision-making with a series of procedures, from collection of information to risk monitoring, state analysis and implementation and evaluation of management [11]. In short, SMEs should establish a good relationship with suppliers in the process of human resource management outsourcing by maintaining a smooth and effective communication channels, strengthening the monitoring mechanism and constructing warning system to improve the efficiency of human resource outsourcing risk management.

\section{References}

[1] [R.A. Noe, Human Resource Management: Gaining a Competitive Advantage (McGraw, Hill Irwin and 2000), p.45-62.

[2] M.A. Huselid: Social Science Electronic Publishing, Vol. 38 (1995) No.3, p.635-672.

[3] C.R. Greer and D.A. Gray: Academy of Management Executive, Vol. 13 (1999) No.3, p.85-96.

[4] L.Q. Wei and Y. Wang: Human Resource Development of China, Vol. 12 (2003) No.1, p.23-26. (In Chinese)

[5] Michel Tremblay, Michel Patry and Paul Lanoie: International Journal of Human Resource Management, Vol. 19 (2008) No.4, p.683-715.

[6] R.M. Zhao: Human Resource Development of China, Vol. 12 (2003) No.1, p.30-33. (In Chinese)

[7] M. Belcourt: Human Resource Management Review, Vol. 16 (2004) No.2, p.269-279.

[8] Y. Wang: Journal of Xinyang College of Agriculture \& Forestry, Vol. 25 (2015) No.4, p.41-43. (In Chinese)

[9] V. Bitsch and G.A. Kassa: Journal of Agricultural \& Applied Economics, Vol. 38 (2006) No.1, p.123-136.

[10]K.M. Gilley and C.R. Greer: Journal of Business Research, Vol. 57 (2004) No.3, p.232-240.

[11]E. Galanaki and N. Papalexandris: International Journal of Manpower, Vol. 26 (2005) No.4, p.382-396. 